\title{
Carbon Metabolism in Microcystis under Low Light Intensities
}

\author{
By G. H. J. KRÜGER广 AND F. JÜTTNER* \\ Institut für Chemische Pflanzenphysiologie der Universität, Corrensstrasse 41, \\ D-74 Tübingen, West Germany
}

(Received 5 November 1979; revised 18 January 1980)

The rate of total ${ }^{14} \mathrm{CO}_{2}$ incorporation in the bloom-forming cyanobacterium Microcystis varied with light intensity, being minimal at 10 lux and increasing at both higher and lower intensities. The total labelling of compounds arising from phosphoenolpyruvate carboxylation (aspartate, glutamate and citrate) showed a minimum just below the light compensation point. At lower light intensities a marked increase in the percentage labelling of these compounds from ${ }^{14} \mathrm{CO}_{2}$ occurred, together with a decrease in that of sugar phosphates and phosphoglycerate. The operation of the reductive pentose phosphate pathway was retarded at low light intensities; with increasing intensities the synthesis of sugars was favoured in relation to that of amino acids. This regulation of the route of $\mathrm{CO}_{2}$ fixation is discussed in relation to the survival of cyanobacteria under unfavourable environmental conditions.

\section{INTRODUCTION}

The reductive pentose phosphate pathway is the main route of cyanobacterial $\mathrm{CO}_{2}$ fixation in the light (Norris et al., 1955; Pelroy \& Bassham, 1972; Ihlenfeldt \& Gibson, 1975; Weathers \& Allen, 1978). In the dark, an alternative $\mathrm{CO}_{2}$ fixation reaction leads to the labelling of aspartate and glutamate (Moses et al., 1959). However, the light intensities which induce a change in the rates of these reactions are not known. Jansz \& Maclean (1973) reported that the type of incubation vessel used had a marked influence on the mechanism of $\mathrm{CO}_{2}$ fixation in Anacystis nidulans, owing to differences in the quantity of light received by the cells. In vessels with a long light-path radioactivity from ${ }^{14} \mathrm{CO}_{2}$ was incorporated mostly into aspartate and to a smaller extent into glutamate; in those with a short light-path sugar phosphates and phosphoglycerate were the major radioactive products. Contradictory results were obtained in subsequent experiments performed under low and high light intensities, the ratio of sugar phosphates plus phosphoglycerate to aspartate being 8:1 under low intensities and 2.5:1 under high intensities. The interpretation of these results is complicated because relatively light and dark zones exist in the dense suspensions employed and consequently individual cells were subjected to varying conditions. Unequivocal information on the effect of different light intensities can only be obtained if mutual shading of the cells is restricted to a minimum. In this communication we describe the patterns of ${ }^{14} \mathrm{CO}_{2}$ incorporation in dilute suspensions of Microcystis incubated at different light intensities in vessels with a short light-path which produced an approximately unicellular layer.

\section{METHODS}

Organism and culture. Microcystis 7005 (Stanier et al., 1971) was obtained from Professor R. Y. Stanier, Institut Pasteur, Paris, France, and cultivated as described by Jüttner (1977). The cultures were proven to be axenic by plating on DEV-agar (Merck no. 11471).

$\uparrow$ Present address: Department of Botany, University of the Orange Free State, Bloemfontein 9300, South Africa. 


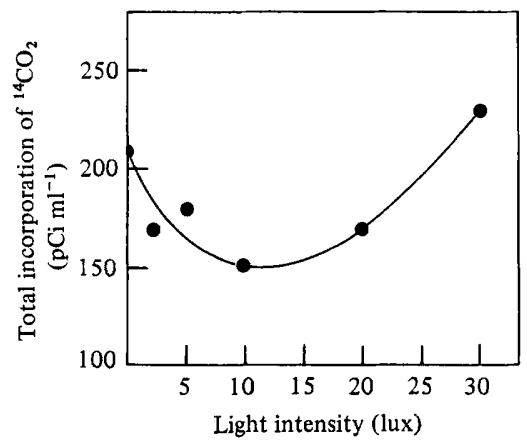

Fig. 1

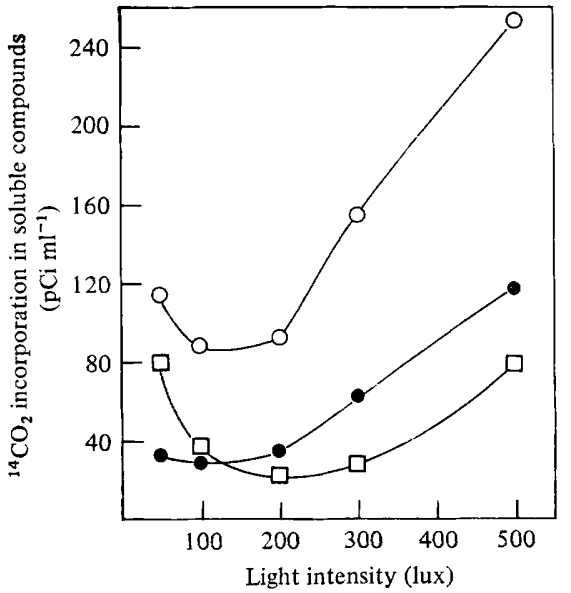

Fig. 2

Fig. 1. Total ${ }^{14} \mathrm{CO}_{2}$ incorporation in Microcystis at different light intensities.

Fig. 2. Incorporation of ${ }^{14} \mathrm{CO}_{2}$ label in soluble aspartate $(\bigcirc)$, glutamate $(\Theta)$ and citrate/isocitrate ( $\square$ ) at different light intensities.

Incorporation of ${ }^{14} \mathrm{CO}_{2}$. Several Microcystis cultures (containing 2.6 to $5 \cdot 5 \mu \mathrm{g}$ chlorophyll $a \mathrm{ml}^{-1}$ ) were mixed, divided into $50 \mathrm{ml}$ portions, and incubated under low light intensity in an incubator shaker for 1 to $4 \mathrm{~h}$. To measure ${ }^{14} \mathrm{CO}_{2}$ incorporation at each light intensity, a $50 \mathrm{ml}$ culture was centrifuged, resuspended in $50 \mathrm{ml}$ of 10-fold diluted medium ( $\mathrm{pH} \mathrm{7.7)}$ and placed in a cuvette of Plexiglas (total volume $70 \mathrm{ml}, 2.5 \mathrm{~mm}$ light-path) which was aerated from below $\left[0.05 \%(\mathrm{v} / \mathrm{v}) \mathrm{CO}_{2}\right.$ in air]. The illumination was supplied by 1 to 3 fluorescent tubes (Osram Interna 39/20 W) which were either partly shaded or placed at different distances from the cuvette. The light intensity (1 lux $\approx 5 \mathrm{erg} \mathrm{cm}^{-2} \mathrm{~s}^{-1}$ ) was determined with a standard lux meter (Lange, Berlin). After adaptation for $15 \mathrm{~min}$ to the light intensity of a particular treatment, $100 \mu \mathrm{Ci}$ of $\mathrm{NaH}^{14} \mathrm{CO}_{3}$ solution [100 $\left.\mu \mathrm{Ci} \mathrm{ml}^{-1}, 59 \cdot 3 \mathrm{mCi} \mathrm{mmol}^{-1}\left(2 \cdot 19 \mathrm{GBq} \mathrm{mmol}{ }^{-1}\right)\right]$ was added. After incubation for $5 \mathrm{~min}$, the reaction was stopped by draining the cyanobacterial suspension into $50 \mathrm{ml}$ boiling ethanol and the suspension was boiled for $2 \mathrm{~min}$.

Determination of total $\mathrm{CO}_{2}$ incorporation. The volume of the ethanolic suspension was adjusted to $100 \mathrm{ml}$, glacial acetic acid $(20 \mu \mathrm{l})$ was added to a $500 \mu \mathrm{l}$ sample and the sample was dried in a stream of $\mathrm{N}_{2}$ at $50{ }^{\circ} \mathrm{C}$. The residue was dissolved in $500 \mu \mathrm{l}$ water and counted by liquid scintillation after adding $10 \mathrm{ml}$ Aquasol.

Chromatographic determination of the soluble compounds. Acetic acid $(0.5 \mathrm{ml})$ was added to the ethanolic suspension to give a $\mathrm{pH}$ below 4.0 , and the sample was bubbled with $\mathrm{N}_{2}$ for 5 min. The suspension was centrifuged and the supernatant was dried at $30^{\circ} \mathrm{C}$ in a rotary evaporator, redissolved in $300 \mu \mathrm{I}$ water and stored at $-18^{\circ} \mathrm{C}$. A $5 \mu \mathrm{l}$ sample was applied to a thin-layer plate and separated by electrophoresis and chromatography, essentially as described by Schürmann (1969).

Determination of total sugars and amino acids. A $5 \mathrm{ml}$ sample of the ethanolic suspension was brought to dryness. The residue was hydrolysed in $1 \mathrm{ml} 8 \mathrm{M}-\mathrm{HCl}$ at $110^{\circ} \mathrm{C}$ for $24 \mathrm{~h}$. The sample was again dried, redissolved in $2 \mathrm{ml} \mathrm{0.1} \mathrm{M-HCl}$ and separated on an ion-exchange resin (Dowex 50 in $\mathrm{H}^{+}$form; $5 \mathrm{~cm} \times 1.0 \mathrm{~cm}$ i.d.). The sugars were eluted with $10 \mathrm{ml}$ distilled water and subsequently the amino acids with $5 \times 2 \mathrm{ml}$ $3 \mathrm{M}-\mathrm{NH}_{4} \mathrm{OH}$ and $25 \mathrm{ml}$ distilled water. The fractions were counted in a liquid scintillation counter after concentration.

Chlorophyll determination. Chlorophyll was extracted from $3 \mathrm{ml}$ cyanobacterial suspension with $3 \mathrm{ml}$ methanol and its concentration was determined from the absorbance at $666 \mathrm{~nm}$ (Ogawa \& Vernon, 1971).

\section{RESULTS AND DISCUSSION}

Total $\mathrm{CO}_{2}$ incorporation in Microcystis followed a linear relationship with light intensity over a wide range of intensities. However, $\mathrm{CO}_{2}$ fixation was higher in the dark than at low light intensities, a minimum being observed at $10 \mathrm{lux}$, well below the light compensation point (Fig. 1).

Chromatographic separation of the water-soluble metabolites from ${ }^{14} \mathrm{CO}_{2}$ fixation over 5 min demonstrated that the ${ }^{14} \mathrm{C}$ label of aspartate, glutamate and citrate/isocitrate (the 


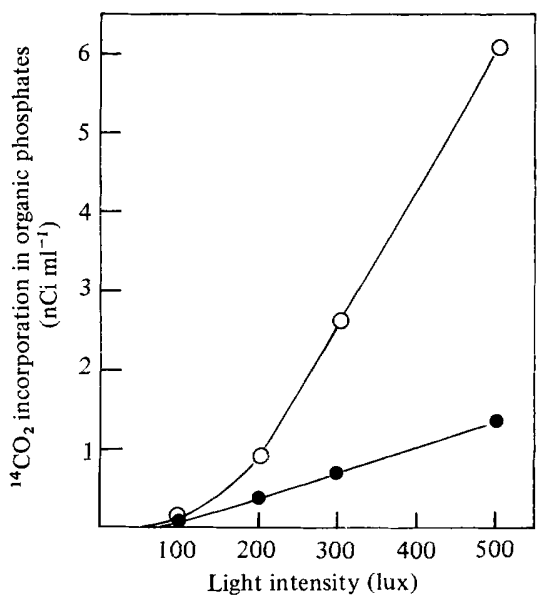

Fig. 3

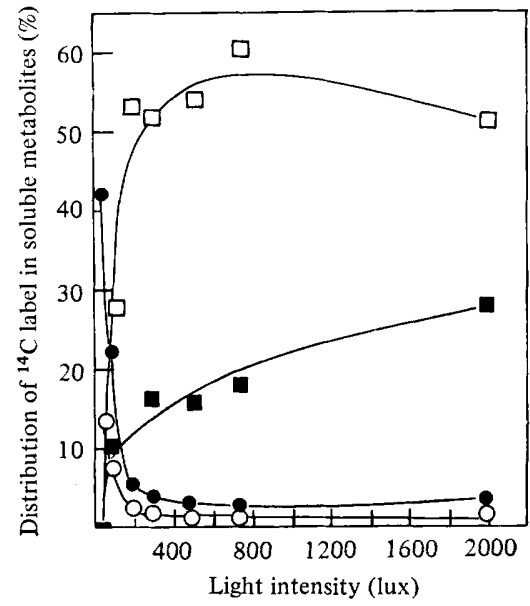

Fig. 4

Fig. 3. Incorporation of ${ }^{14} \mathrm{CO}_{2}$ label in sugar phosph ates $(O)$ and phosphoglycerate $(O)$ at different light intensities.

Fig. 4. Percentage distribution of ${ }^{14} \mathrm{C}$ label in soluble metabolites, sugar phosphates ( $\square$ ), phosphoglycerate $(\square)$, aspartate $(O)$ and citrate/isocitrate $(O)$, at different light intensities.

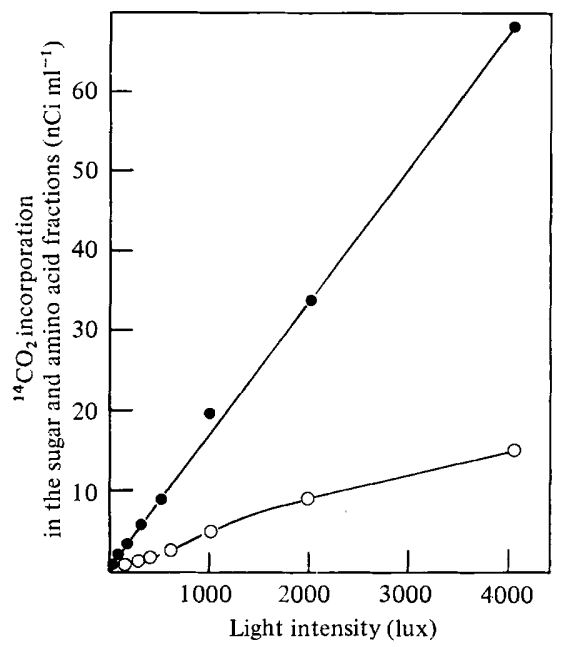

Fig. 5. Incorporation of ${ }^{14} \mathrm{CO}_{2}$ label in the sugar (O) and amino acid (O) fractions at different light intensities.

latter were not separated) also showed a light-dependent minimum which, however, was shifted to a higher light intensity (Fig. 2). This value corresponded with the light compensation point (close to 200 lux) determined for a similar Microcystis strain (Jüttner, 1977). Labelled sugar phosphates and phosphoglycerate could not be detected at light intensities below 100 lux. Above this value, the label in these compounds increased rapidly and then constituted the main fraction of the labelled metabolites (Fig. 3). The percentage distribution of the label in sugar phosphates and phosphoglycerate increased rapidly at a light intensity of 200 lux (Fig. 4) with a corresponding decrease in the label of citrate, aspartate and glutamate (not shown).

These fixation patterns indicate a severely restricted function of the reductive pentose phosphate cycle under low light intensities. However, the labelling of aspartate, glutamate 
and citrate, which are typical compounds of phosphoenolpyruvate carboxylation, was much less affected. Phosphoenclpyruvate carboxylation is of importance for the regeneration of intermediates of the citrate cycle utilized in the synthesis of amino acids. There is no other pathway for organic acid pool regeneration, due to the low activity of the glyoxylate pathway (Pearce \& Carr, 1967) and the lack of 2-oxoglutarate decarboxylase (Pearce et al., 1969). These results explain the different ${ }^{14} \mathrm{CO}_{2}$ fixation patterns reported for Anacystis by Richter (1961) and Kandler (1961). If dense suspensions and long light-paths are used the labelling of aspartate and glutamate is favoured. However, the fixation pattern of Calvin cycle products is obtained under high light intensities and if vessels with short light-paths and dilute suspensions are used. Increased light intensities stimulate the formation of sugars which form the storage product glycogen; the synthesis of amino acids is comparatively less affected (Fig. 5). This control system is of importance for the survival of cyanobacteria under varying environmental conditions: if sufficient light energy is available reserve material is formed whereas under limited light conditions the synthesis of essential compounds necessary for the maintenance of cell activity is favoured.

The financial assistance of the Deutsche Forschungsgemeinschaft and C.S.I.R., South Africa, is gratefully acknowledged.

\section{REFERENCES}

IhlenFeldT, M. J. A. \& Gibson, J. (1975). $\mathrm{CO}_{2}$ fixation and its regulation in Anacystis nidulans (Synechococcus). Archives of Microbiology 102, 13-21.

JANSZ, E. R. \& MACLEAN, F. I. (1973). $\mathrm{CO}_{2}$ fixation by the blue-green alga Anacystis nidulans. Canadian Journal of Microbiology 19, 497-504.

JÜTTNER, F. (1977). Thirty liter tower type pilot plant for the mass cultivation of light- and motionsensitive planktonic algae. Biotechnology and Bioengineering 19, 1679-1687.

KANDLER, O. (1961). Verteilung von $\mathrm{C}^{14}$ nach Photosynthese in $\mathrm{C}^{14} \mathrm{O}_{2}$ von Anacystis nidulans. Naturwissenschaften 48, 604.

Moses, V., Holm-Hansen, O. \& Calvin, M. (1959). Nonphotosynthetic fixation of carbon dioxide by three microorganisms. Journal of Bacteriology 77, 70-78.

Norris, L., Norris, R. E. \& Calvin, M. (1955). A survey of the rates and products of short-term photosynthesis in plants of nine phyla. Journal of Experimental Botany 6, 64-74.

Ogawa, T. \& Vernon, L.P. (1971). Increased content of cytochromes 554 and 562 in Anabaena variabilis. Biochimica et biophysica acta 226, 8897.

Pearce, J. \& Carr, N. G. (1967). The metabolism of acetate by the blue-green algae, Anabaena

variabilis and Anacystis nidulans. Journal of General Microbiology 49, 301-313.

Pearce, J., Leach, C. K. \& CARR, N. G. (1969). The incomplete tricarboxylic acid cycle in the blue-green alga Anabaena variabilis. Journal of General Microbiology 55, 371-378.

Pelroy, R. A. \& Bassham, J. A. (1972). Photosynthetic and dark carbon metabolism in unicellular blue-green algae. Archiv für Mikrobiologie 86, 25-38.

RICHTER, G. (1961). The lack of diphosphofructose aldolase in two photosynthetic organisms: Anacystis nidulans and Rhodopseudomonas spheroides. Biochimica et biophysica acta 48, 606-608.

SchürmanN, P. (1969). Separation of phosphate esters and algal extracts by thin-layer electrophoresis and chromatography. Journal of Chromatography 39, 507-509.

Stanier, R. Y., Kunisawa, R., Mandel, M. \& Cohen-Bazire, G. (1971). Purification and properties of unicellular blue-green algae (Order Chroococcales). Bacteriological Reviews 35, 171205.

WeAtHers, P. J. \& Allen, M. M. (1978). Variations in short term products of inorganic carbon fixation in exponential and stationary phase cultures of Aphanocapsa 6308. Archives of Microbiology 116, 231-234. 